\title{
Comparative study on the effect of ethnicity on wisdom tooth eruption
}

A. Olze ${ }^{1}$, P. van Niekerk ${ }^{2}$, T. Ishikawa ${ }^{3}$, B. L. Zhu ${ }^{3}$, R. Schulz ${ }^{4}$, H. Maeda ${ }^{3}$ and A. Schmeling ${ }^{4}$

(1) Institut für Rechtsmedizin, Charité-Universitätsmedizin Berlin, Turmstrasse 21, 10553 Berlin, Germany

(2) Department of Oral Pathology and Oral Biology, University of Pretoria, P.O. Box 1266, Pretoria, 0001, South Africa

(3) Department of Legal Medicine, Osaka City University Medical School, Asahi-Machi 1-4-3, Abeno, Osaka 545-8585, Japan

(4) Institut für Rechtsmedizin, Röntgenstrasse 23, 48149 Münster, Germany

\begin{abstract}
The current knowledge base for evaluating the influence of ethnic origin on wisdom tooth eruption is still inadequate. We therefore analyzed and compared the chronology of wisdom tooth eruption in three ethnic populations-German, Japanese, and black South Africanbased on evidence from 2,482 conventional orthopantomograms. The investigated German population ranked in the middle in terms of the age of wisdom tooth eruption. The black South African population was the fastest and the Japanese population the slowest in terms of reaching the respective eruption stages. Population-specific reference data should be used when evaluating wisdom tooth eruption for the purpose of forensic age estimation.
\end{abstract}

\section{Introduction}

Forensic age estimation in living subjects is a current focus of research interest $[2,4,5,11$, 12, 14-18]. Wisdom tooth mineralization has been the main criterion used for dental age diagnosis in adolescents so far. Olze et al. [13] studied the effects of ethnicity on wisdom tooth mineralization. To summarize, the authors concluded that their Caucasoid population ranked in the middle of the investigated ethnic groups in terms of dental development as defined by their age at reaching the large majority of mineralization stages. The investigated Asiatic subjects were a mean 0.5-3 years older and the investigated African subjects 0.5-2 years younger than their Caucasian counterparts when they reached the same stages of dental development. The influence of ethnic origin on wisdom tooth eruption is still poorly understood. In the present study, we therefore analyzed and compared the chronological course of wisdom tooth eruption in German, Japanese, and South African populations, respectively.

\section{Materials and methods}

We analyzed a total of 2,482 conventional orthopantomograms from 666 German, 1,300 Japanese, and 519 black South African subjects aged 12-26, with known dates of birth. The patient identification number, sex, date of birth, and date of X-ray were recorded for each test subject. Each patient's age was calculated based on the date of birth and the date of X-ray. Table 1 shows the age, sex, and ethnic distribution of the sample sets. 
Table 1 Age and sex distribution of the ethnic populations studied

\begin{tabular}{|l|l|l|l|l|l|l|l|l|}
\hline \multirow{2}{*}{ Age (years) } & \multicolumn{3}{l}{ German } & \multicolumn{3}{l|}{ Japanese } & \multicolumn{3}{l|}{ Black South African } \\
\cline { 2 - 3 } & Men & Women & Men & Women & Men & Women \\
\hline 12 & 0 & 13 & 0 & 0 & 5 & 3 \\
\hline 13 & 0 & 28 & 0 & 0 & 8 & 4 \\
\hline 14 & 2 & 33 & 2 & 3 & 3 & 4 \\
\hline 15 & 5 & 48 & 9 & 11 & 8 & 5 \\
\hline 16 & 5 & 45 & 12 & 23 & 9 & 12 \\
\hline 17 & 1 & 49 & 9 & 14 & 15 & 6 \\
\hline 18 & 5 & 41 & 32 & 57 & 21 & 7 \\
\hline 19 & 11 & 51 & 69 & 98 & 34 & 6 \\
\hline 20 & 19 & 39 & 69 & 108 & 37 & 11 \\
\hline 21 & 22 & 60 & 71 & 119 & 48 & 9 \\
\hline 22 & 18 & 31 & 73 & 118 & 63 & 12 \\
\hline 23 & 18 & 42 & 98 & 110 & 55 & 12 \\
\hline 24 & 19 & 33 & 68 & 54 & 58 & 7 \\
\hline 25 & 14 & 9 & 34 & 33 & 33 & 6 \\
\hline 26 & 5 & 0 & 3 & 3 & 13 & 2 \\
\hline Total & 144 & 522 & 549 & 751 & 410 & 106 \\
\hline
\end{tabular}

The following staging system was used for the classification of third molar eruption (Fig. 1):

Stage A Occlusal plane covered with alveolar bone

Stage B Alveolar emergence; complete resorption of alveolar bone over occlusal plane Stage C Gingival emergence; penetration of gingiva by at least one dental cusp Stage D Complete emergence in occlusal plane

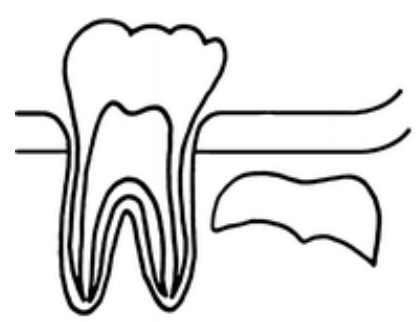

A

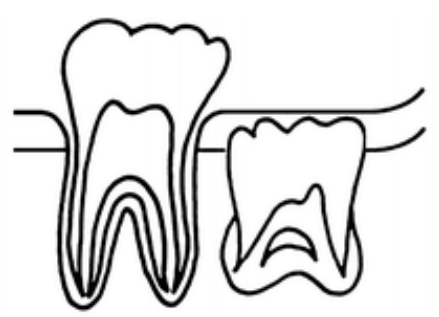

B

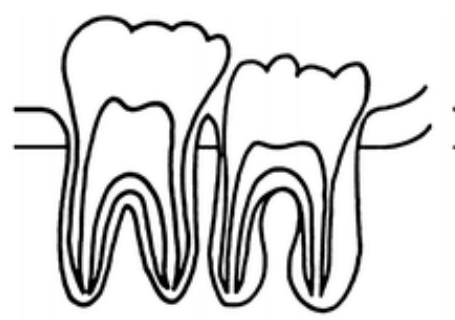

C

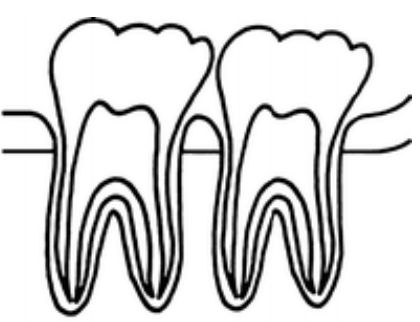

D

Fig. 1 Stages $\mathbf{A}$ to $\mathbf{D}$ of third molar eruption 
Impacted wisdom teeth were excluded from the analysis. Mesially, distally, and vestibuloorally angulated third molars were classified as impacted as recommended by Archer [1] and Wolf and Haunfelder [19]. Wisdom teeth with an unclear direction of emergence also were not included in the analysis. All staging was carried out by the same observer (Olze).

Statistical analyses were performed using the SPSS software. To cope with outliers and/or skew distributions, differences between groups of interest were analyzed using nonparametric tests (Kruskal-Wallis test for multiple groups, Mann-Whitney $U$ test for two independent groups, and Wilcoxon test for paired observations). Exact versions of the tests were used to handle major differences in sample sizes. The level of significance was defined as $p<0.05$ (two-sided tables).

\section{Results}

Table 2 provides various statistical data on the age of emergence of tooth 18 in the different population groups defined by ethnic origin and sex. Mean values with standard deviation ranges and median values with lower and upper quartiles are given. Statistically significant differences between different ethnic groups are also indicated. A similar structure of significance was derived for teeth 28,38 , and 48. 
Table 2 Statistical data on the age of emergence of tooth 18, by stage, and significant population differences

\begin{tabular}{|c|c|c|c|c|}
\hline Stage & Sample & $n$ & Mean age ${ }^{a}$ & Median, LQ, UQ \\
\hline \multirow{6}{*}{ A } & German men & 14 & $18.9 \pm 3.4^{c}$ & $18.3,15.5,21.9$ \\
\hline & German women & 146 & $16.6 \pm 3.0^{b, c}$ & $16.0,14.1,18.8$ \\
\hline & Japanese men & 43 & $19.9 \pm 2.9^{d}$ & $20.1,17.5,22.0$ \\
\hline & Japanese women & 98 & $19.9 \pm 2.7^{b, c}$ & $20.0,18.3,22.1$ \\
\hline & South African men & 18 & $15.7 \pm 3.5^{c, d}$ & $14.6,13.0,17.6$ \\
\hline & South African women & 15 & $14.8 \pm 1.9^{\mathrm{c}, \mathrm{d}}$ & $14.9,13.0,16.0$ \\
\hline \multirow{6}{*}{ B } & German men & 32 & $20.8 \pm 2.7^{c}$ & $21.2,19.7,22.9$ \\
\hline & German women & 172 & $18.9 \pm 3.2^{b}$ & $18.4,16.3,21.4$ \\
\hline & Japanese men & 93 & $20.9 \pm 2.8^{d}$ & $20.6,19.0,23.3$ \\
\hline & Japanese women & 129 & $20.6 \pm 2.2^{b, c}$ & $20.4,19.3,22.3$ \\
\hline & South African men & 44 & $17.8 \pm 2.8^{\mathrm{c}, \mathrm{d}}$ & $17.7,16.2,19.3$ \\
\hline & South African women & 16 & $18.0 \pm 3.0^{d}$ & $17.2,15.4,21.3$ \\
\hline \multirow{6}{*}{ C } & German men & 15 & $22.1 \pm 2.3$ & $21.3,20.1,24.2$ \\
\hline & German women & 45 & $20.3 \pm 2.1^{\mathrm{b}, \mathrm{c}}$ & $20.2,18.8,21.8$ \\
\hline & Japanese men & 91 & $21.5 \pm 2.2$ & $21.5,19.6,23.5$ \\
\hline & Japanese women & 133 & $21.2 \pm 2.0^{b, c}$ & $20.9,19.4,22.7$ \\
\hline & South African men & 24 & $20.7 \pm 2.5$ & $20.5,18.6,22.6$ \\
\hline & South African women & 6 & $18.7 \pm 1.6^{\mathrm{c}, \mathrm{d}}$ & $19.2,17.2,19.7$ \\
\hline \multirow{6}{*}{ D } & German men & 31 & $23.4 \pm 2.3$ & $24.0,21.9,25.2$ \\
\hline & German women & 3 & $24.0 \pm 0.8$ & $24.2,23.2,24.7$ \\
\hline & Japanese men & 204 & $22.4 \pm 2.0$ & $22.7,21.0,23.9$ \\
\hline & Japanese women & 223 & $22.3 \pm 1.8$ & $22.4,21.2,23.6$ \\
\hline & South African men & 284 & $22.7 \pm 2.1$ & $22.8,21.3,24.3$ \\
\hline & South African women & 60 & $22.0 \pm 2.6$ & $22.3,20.4,23.8$ \\
\hline
\end{tabular}


$n$ Number of cases; $L Q$ lower quartile; $U Q$ upper quartile

${ }^{a}$ Mean age (in years) \pm standard deviation (SD)

${ }^{\mathrm{b}}$ Statistically significant difference between Japanese and Germans $(p<0.05)$

${ }^{c}$ Statistically significant difference between South Africans and Germans $(p<0.05)$

${ }^{\mathrm{d} S}$ Statistically significant difference between Japanese and South Africans $(p<0.05)$

\section{Discussion}

Only a few comparison studies on wisdom tooth eruption have been published so far, and these studies are limited to gingival eruption.

Fanning [7] investigated gingival third molar emergence in American white men $(n=2,370)$ and women $(n=1,053)$ from the Boston area (age $=13-22$ years) and compared the data with that from a black African population described by Chagula [6]. The Americans' upper wisdom teeth emerged at a mean age of 20.5 years in both men and women, and the lower wisdom teeth emerged at mean ages of 19.8 years in men and 20.4 years in women. According to the figures published by Chagula [6], dental development in Africans is faster: Their upper and lower wisdom teeth erupted at the ages of 13-16 and 17-20 years, respectively, which is 2.5 and 1.25 years earlier than in their white American counterparts.

Similarly, Garn et al. [8], who investigated the eruption of permanent teeth in 953 black and 998 white Americans, found that upper wisdom teeth of black Americans emerged 3.7 years earlier and lower wisdom teeth 5.6 years earlier than in white Americans.

In a review of the literature on growth and development in Japan, Kimura [10] provided Japanese statistics on third molar emergence (mean age $=19.8$ years in men and 21.0 years in women). After comparing his data with that of Fanning [7] for white North Americans, Kimura concluded that the figures are in close agreement.

Hassanali [9] compared third molar eruption in 1,343 Africans and 1,092 Asians from Kenya. In the African subjects, the lower wisdom teeth emerged at a mean age of 17.6-18.3 years and the upper wisdom teeth at 18.5-18.9 years. The corresponding ages in the Asian subjects were 19.9-20.3 years for the lower wisdom teeth and 20.7-21.0 years for the upper wisdom teeth. Accordingly, dental development in the African Kenyans occurred roughly 2-3 years faster. Hassanali therefore concluded that wisdom tooth eruption began at the age of 13 in the investigated African subjects and that all four wisdom teeth had erupted in 50\% of these subjects by the age of 18.5 years. In the investigated Asian subjects, on the other hand, wisdom tooth eruption began at the age of 15 , and all four wisdom teeth had erupted in $50 \%$ of the group by the age of 21.5 years.

In our study, the assessment of stage $\mathrm{C}$ (gingival eruption) turned out to be quite difficult in some cases. In the cases, in which the gingiva was not clearly recognizable and the dental surface was at the level of the expected gingiva, no assessment was made. When the surface of the teeth was clearly above the expected gingiva and below the occlusal plane, the teeth were classified as stage $\mathrm{C}$. This method might have led to the fact that the statistical scores for stage $\mathrm{C}$ are a little to high in our study. However, this would not have a 
negative effect on the examined individuals in case of age estimations in criminal proceedings.

The present study is, to the best of our knowledge, the first to supply comparative reference data on wisdom tooth eruption for Caucasian, Asian, and African subjects of forensically relevant age whose dates of birth have been verified under standardized conditions. All age estimates were performed by the same observer to eliminate potential interobserver error. We found that the investigated German population has an intermediate rate of dental development as determined by comparing the different ages of third molar eruption. The defined eruption stages occurred at earlier ages in the investigated South African population and at later ages in the Japanese population. Statistically significant population differences were observed in women at stages A, B, and C. The South African women reached the target stages a mean 1.6-1.8 years earlier than the German women, whereas the Japanese women were a mean 0.9-3.3 years older than their German counterparts. The men also exhibited statistically significant population differences at stages A and B. The South African men were a mean 3.0-3.2 years younger than the German men at these stages of development, and the Japanese men were a mean 3.1-4.2 years older than their South African counterparts.

The population differences observed here may be due to differences in palatal dimensions between the ethnic groups surveyed. The largest palatal dimensions are observed in Africans and the smallest in Asians, with Caucasians ranking in the middle [3]. Inadequate space in the maxillary crest may lead to delayed wisdom tooth eruption or impaction [7].

According to our study results, we conclude that forensic age assessments should be based on population-specific reference data.

\section{Acknowledgments}

This study was supported by a grant from the Deutsche Forschungsgemeinschaft (SCHM 1609/1-1). The authors would like to thank Prof. K-D Wernecke, Institute of Medical Biometrics, Charité-Universitätsmedizin Berlin, for his advice on the statistical aspects of the study.

\section{References}

1. Archer WH (1955) Die Chirurgie des Mundes und der Zähne. Medica, Stuttgart

2. Braga J, Heuze Y, Chabadel O, Sonan NK, Gueramy A (2005) Non-adult dental age assessment: correspondence analysis and linear regression versus Bayesian predictions. Int J Legal Med 119:260-274

3. Byers SN, Churchill SE, Curran B (1997) Identification of Euro-Americans, AfroAmericans, and Ameridians from palatal dimensions. J Forensic Sci 42:3-9

4. Cameriere R, Ferrante L, Cingolani M (2006) Age estimation in children by measurement of open apices in teeth. Int J Legal Med 120:49-52 
5. Cameriere R, Ferrante L, Mirtella D, Cingolani M (2006) Carpals and epiphyses of radius and ulna as age indicators. Int J Legal Med 120:143-146

6. Chagula WK (1960) The age at eruption of third permanent molars in male East Africans. Am J Phys Anthropol 18:77-82

7. Fanning EA (1962) Third molar emergence in Bostonians. Am J Phys Anthropol 20:339_ 346

8. Garn SM, Wertheimer F, Sandusky ST, McCann MB (1972) Advanced tooth emergence in Negro individuals. J Dent Res 51:1506

9. Hassanali J (1985) The third permanent molar eruption in Kenyan Africans and Asiens. Ann Hum Biol 12:517-523

10. Kimura K (1984) Studies on growth and development in Japan. Yearb Phys Anthropol 27:179-214

11. Mühler M, Schulz R, Schmidt S, Schmeling A, Reisinger W (2006) The influence of slice thickness on assessment of clavicle ossification in forensic age diagnostics. Int $\mathrm{J}$ Legal Med 120:15-17

12. Olze A, Bilang D, Schmidt S, Wernecke K-D, Geserick G, Schmeling A (2005) Validation of common classification systems for assessing the mineralization of third molars. Int J Legal Med 119:22-26

13. Olze A, Schmeling A, Taniguchi M, Maeda $H$, van Niekerk $P$, Wernecke KD, Geserick $G$ (2004) Forensic age estimation in living subjects: the ethnic factor in wisdom tooth mineralization. Int J Legal Med 118:170-173

14. Paewinsky E, Pfeiffer H, Brinkmann B (2005) Quantification of secondary dentine formation from orthopantomograms - a contribution to forensic age estimation methods in adults. Int J Legal Med 119:27-30

15. Prieto JL, Barberia E, Ortega R, Magana C (2005) Evaluation of chronological age based on third molar development in the Spanish population. Int J Legal Med 119:349-354

16. Schmeling A, Baumann U, Schmidt S, Wernecke KD, Reisinger W (2006) Reference data for the Thiemann-Nitz method of assessing skeletal age for the purpose of forensic age estimation. Int J Legal Med 120:1-4

17. Schmeling A, Schulz R, Danner B, Rösing FW (2006) The impact of economic progress and modernization in medicine on the ossification of hand and wrist. Int $\mathrm{J}$ Legal Med 120:121-126

18. Schulz R, Mühler M, Mutze S, Schmidt S, Reisinger W, Schmeling A (2005) Studies on the time frame of ossification of the medial epiphysis of the clavicle as revealed by CT scans. Int J Legal Med 119:142-145

19. Wolf H, Haunfelder D (1960) Zahnärztliche Mundchirurgie für Studierende der Zahnheilkunde. Berlinische Verlagsanstalt, Berlin, pp 59-67 